\title{
O papel da mulher intelectual na libertação da subalternidade de gênero no mundo pós-colonial.
}

\author{
Cleiton Ricardo das Neves \\ Amélia Cardoso de Almeida ${ }^{* *}$
}

\begin{abstract}
Resumo: O colonialismo promove a despersonalização do ser colonizado, e nesse processo, o ser colonizado é também silenciado, ou seja, não lhe é permitido que se autorrepresente, sendo que sua representação é feita sempre pelo Outro colonizador. Há um elemento ainda mais grave nesse processo de silenciamento ${ }^{1}$ do subalterno, que é a questão de gênero dentro da própria empresa colonial, pois a mudez da mulher colonizada é ainda mais preocupante, já que esta é duplamente silenciada, subordinada tanto pelo patriarcado quanto pelo colonialismo. O presente artigo se propõe a analisar as questões relacionadas ao gênero feminino que envolvem as sociedades póscoloniais e principalmente o papel desempenhado pela mulher intelectual oriunda do mundo colonizado ao problematizar a mudez da mulher subalterna. Para tanto, utilizaremos como base a teoria pós-colonial, especificamente o artigo "Pode o subalterno falar?" da intelectual indiana Gayatri Chakravorty Spivak.

Palavras-chave: Pós-Colonialismo; Gênero; Cultura.
\end{abstract}

Abstract: Colonialism promotes depersonalization of the being colonized, and in the process, the colonized is also silenced, that is, you are not allowed that auto represent, and its representation is always made by the Other colonizer. There is an even more serious element in this silencing process of the subaltern, which is the issue of gender inside the colonial enterprise, because the silence of the colonized woman is even more worrying, as this is doubly silenced, subordinate to both the patriarchy as colonialism. This article aims to discuss matters related to the female gender involving post-colonial societies and especially the role played by intellectual woman coming from the colonized world to question the silence of the subaltern woman. For so much, based on the post- colonial theory, specifically the article "Can the subaltern speak?" from Indian intellectual Gayatri Chakravorty Spivak.

Keywords: Post- Colonialism; Gender; Culture.

\footnotetext{
* Cleiton Ricardo das Neves é Mestre em Hístória pela UFG e coordenador do Grupo de Estudos em Teorias do Pós-Colonialismo da PUC-GO.

** É graduada em História pela pela Pontifícia Universidade Católica de Goiás. Mestranda em História pela mesma instituição e membra do Grupo de Estudos e Pesquisa em Pós-colonialismo e Critica Cultural (GEPPECC) da PUC-GO.

${ }^{1} O$ silenciamento refere-se ao fato de que os sujeitos subalternos no mundo colonial não possuem o privilégio de que sua fala seja ouvida, ou seja, ele não se autorrepresenta. $O$ sujeito subalterno do gênero feminino tem sua voz ainda mais silenciada, pois é subordinado ao colonialismo e ao gênero masculino por meio da cultura patriarcal.
} 
Os estudos pós-coloniais emergiram sob a influência dos Estudos Culturais, mas, de certa forma, emancipando-se destes em função do seu objeto de investigação, que é o mundo colonial vislumbrado principalmente através da literatura. Grande parte da produção intelectual efetivada no seio da corrente pós-colonial é devedora dos subalternity studies. $\mathrm{O}$ grupo intitulado Estudos Subalternos é assim denominado porque produz suas reflexões a partir do marginalizado, do subalterno. O projeto do grupo é principalmente repensar a historiografia indiana a partir da desconstrução da visão elitista produzida pelo colonizador inglês acerca da história indiana.

Repensar a história indiana ou a de qualquer outra sociedade que foi colonizada significa a construção de uma nova história na qual esse colonizado tenha direito à fala e principalmente que sua voz seja ouvida e, nesse sentido, permitir que sua história seja construída a partir de sua própria percepção. Sendo assim, a proposta de Gayatrí Chacravorty Spivak é questionar o problema da mudez do sujeito colonizado, mas principalmente analisar o problema da mudez enfrentado pelo gênero feminino que, segundo a autora, encontra-se ainda mais na obscuridade. Primeiro por ser classificada como uma colonizada, ocupando assim um lugar de subalternidade frente ao colonizador e mais ainda, uma colonizada do gênero feminino que a deixa inferiorizada diante dos outros colonizados do gênero masculino.

Segundo Joan Scott ${ }^{2}$, a partir da década de 1980, a categoria "gênero" foi utilizada para substituir a categoria de "mulher", ou seja, a categoria "gênero" foi apropriada de uma maneira um tanto simples para ser aplicada como sinônimo da categoria "mulher". Segundo a autora, surgiu uma grande quantidade de livros e artigos que, apesar de abordar exclusivamente sobre a história das mulheres, trazia em seus títulos a categoria "gênero" em substituição à categoria "mulheres". Para a autora, tal substituição parece indicar para uma maior neutralidade, por ser uma categoria que pode incluir as mulheres sem as nomear e ao mesmo tempo não exclui os homens. No entanto, podemos observar que o que reforça a ideia da categoria "gênero" como sinônimo da categoria "mulher" é o fato de que a grande maioria dos trabalhos que trazem em seus títulos a categoria "gênero", e não "mulher", seu conteúdo diz respeito exclusivamente à história das mulheres, ou seja, o título sugere tal neutralidade, porém o conteúdo não é neutro.

\footnotetext{
2 Joan Scott nasceu nos Estados Unidos, considerada um dos grandes nomes da crítica feminista atual, especialmente no estudo da categoria de gênero na história. Uma de suas obras principais é o artigo intitulado "Gênero: uma categoria útil para a análise em história", que foi publicado originalmente em 1989.
} 
Podemos aqui dialogar com Joana Maria Pedro ${ }^{3}$ em seu texto intitulado "Relações de gênero como uma categoria transversal na historiografía contemporânea", diz que apesar de Scott ser muito lida e citada no Brasil e nos outros países do Cone-sul, a categoria "gênero" é utilizada, porém o conteúdo continua sendo exclusivamente a respeiro da história das "mulheres". Assim sendo, estas publicações acabam reforçando a ideia presente no senso comum de que a categoria "gênero" é sinônimo da categoría "mulher".

É justamente a desconstruçao da ideia de que a categoria "gênero" é sinônimo da categoria "mulher" que Scott salienta em seu artigo "Gênero: uma categoria útil para a análise em história"( 1995).

Assim diz Scott,

(...) o gênero é igualmente utilizado para designar as relações sociais entre os sexos. $\mathrm{O}$ seu uso rejeita explicitamente as justificativas biológicas, como aquelas que encontram um denominador comum para várias formas de subordinação no fato de que as mulheres têm filhos e que os homens têm uma força muscular superior. O gênero se torna, aliás, uma maneira de indicar as "construções sociais" - a criação inteiramente social das ideias sobre os papéis próprios aos homens e às mulheres. É uma maneira de se referir às origens exclusivamente sociais das identidades subjetivas dos homens e das mulheres (SCOTT, 1995:07).

A categoria "gênero" é mencionada por Spivak também na perspectiva citada acima, principalmente quando afirma: "A construção ideológica de gênero mantém a dominação masculina" (SPIVAK, 2010:67). Ou seja, o gênero feminino é dominado pelo gênero masculino. A autora deixa clara sua intenção em problematizar a questão de gênero no que se refere ao gênero feminino; assim no decorrer de sua obra são mencionadas categorias tais como: "subalterno feminino", "mulher", "mulheres".

Para Scott, as historiadoras feministas partem de três posições teóricas ao abordar a questão de gênero. A primeira é a busca pela compreensão das origens do patriarcado e a mulher como subordinada ao homem cultural, social e principalmente sexualmente, uma vez que são vistas como objetos reprodutivos. Assim, a chave do patriarcado estaria na reprodução e na sexualidade; A segunda posição teórica utiliza-se da tradição marxista, pois a sexualidade é considerada pelo feminismo da mesma forma que o trabalho é considerado para Marx, ou seja, tanto o trabalho quanto a sexualidade são elementos alienantes. Por fim, a terceira posição teórica se baseia no pós-estruturalismo francês ou nas teorias angloamericanas sobre a relação do sujeito como objeto.

\footnotetext{
${ }^{3}$ É historiadora e pesquisadora do Instituto de Estudos de Gênero da Universidade Federal de Santa Catarina.
} 
Seguindo esta classificação feita por Scott quanto às posições teóricas das historiadoras feministas, Spivak, apesar de não ser historiadora, utiliza-as para fazer seus apontamentos como poderemos constatar a seguir.

Spivak é indiana de Calcutá. É graduada em inglês pela Universidade de Calcutá e depois fez mestrado e doutorado em literatura comparada na Universidade Cornell nos Estados Unidos. Sua produção se centra principalmente em questionar o colonialismo e principalmente o patriarcalismo indiano, ambos responsáveis pelo silenciamento da mulher. Spivak busca compreender o sistema patriarcal indiano, questionando e apresentado hipóteses para as causas da subordinação do gênero feminino.

Atualmente, além de atuar como professora de Literatura comparada em várias instituições de ensino dos Estados Unidos, é uma intelectual crítica que se fundamenta no referencial do marxismo, do pós-estruturalismo e também do desconstrutivismo, sendo considerada por muitos como a tradutora de Jacques Derrida. Atua principalmente em questões que abordam a mulher e sua representação, a partir de uma concepção feminista desenvolvida no seio da crítica pós-colonial, porém, como relatamos acima, sua concepção feminista está em diálogo com a crítica feminista atual, embora sua ênfase maior seja as questões de gênero envolvendo a mulher colonizada. Assim, sua posição teórica navega também pelas estruturas políticas e sociais, pois o estudo da questão de gênero não está dissociado das esferas políticas como poderemos assinalar dialogando com Judith Butler. ${ }^{4}$

Assim diz Butler,

Él género en disputa: El feminismo y la subversión de la identidad"(2007): "Para la teoria feminista, es desarollo de un lenguage que represente de manera adecuada y completa as las murejes há sido necesário para promover su visibilidad política" (BUTLER, 2007:46).

Assim, constatamos que a busca pela liberdade da subalternidade de gênero está associada também à liberdade política como forma de as mulheres se autorrepresentarem, tendo assim mais visibilidade também no campo político. Para Spivak, o termo subalterno pode ser atribuído a todo sujeito que é privado do direito à representação política, o que significa que um outro sujeito fala por ele. Nesse sentido, para Spivak e para as teóricas feministas em geral, a luta pela liberdade plena da opressão de gênero também é uma luta política.

\footnotetext{
${ }^{4}$ Judith Butler nasceu nos Estados Unidos. É filósofa pós-estruturalista e principalmente uma das grandes teóricas contemporânea do feminismo. Uma de suas principais obras é "Él género en disputa: El feminismo y la subversión de la identidad" que foi publicado originalmente em inglês no ano de 1999, sendo traduzido para o espanhol em 2007.
} 
Segundo Thomas Bonnici (2005), a visão crítica das teóricas feministas dos anos 1980 concluíu que o feminismo é um produto cultural ocidental e como tal elaborou-se uma categoria universal do gênero feminino, prescindindo de categorias como raça e classe social. Dessa forma, essa categoria não pode ser aplicada, considerando que a realidade cultural e social e principalmente étnica de cada mulher é diferenciada. Assim, a abordagem crítica feminista deve considerar essas especificidades.

Spivak, como analisamos acima, está em sintonia com a crítica feminista ocidental. Seu próprio lócus de enunciação são os Estados Unidos, país considerado como um grande centro imperial mas que, apesar disso, suas concepções feministas consideram o lugar específico no qual o sujeito colonizado feminino é duplamente silenciado, de um lado pelo colonizador e de outro pela cultura patriarcal.

Quando Spivak se refere ao sistema patriarcal, não está considerando a realidade patriarcal ocidental e sim a realidade específica indiana, uma vez que a teoria feminista é oriunda de outra realidade, que é o hemisfério norte, o mundo considerado desenvolvido. Assim, essas teorias questionam as noções de um patriarcado universal, sem considerar outras realidades específicas. Dessa forma, quando tais teorias são aplicadas em outros contextos, deve-se considerar a especificidade sociocultural do gênero feminino. Assim, pode-se considerar que a ideia de opressão não é igual em todos os lugares; logo, a opressão feminina varia de um contexto para outro.

Assim diz Butler,

La creença política de que debe haber una base universal para él feminismo, $y$ de que puede fundarse en una identidad que aparentemente existe en todas las culturas, a menudo va unida a la ideia de que lá opression de las mujeres posee alguna forma específica reconocible dentro de la estructura universal a hegemónica del patriarcado o de la dominación masculina.La ideia de un patriarcado universal há recebido numerosas críticas en años recientes porque no tiene en cuenta el funcionamento (BUTLER, 2007:49).

Segundo Joana Maria (2010), a maneira como as categorias "mulher", “mulheres" e "relações de gênero" foram construídas e depois apropriadas em diferentes realidades podem ser clasificadas através das noções de ondas. Essas ondas podem ser divididas em três fases. A primeira fase se deu a partir da década de 1970, quando a categoría "mulher" foi utilizada com o objetivo de demarcar uma unidade mais radical do movimento feminista. A partir da década de 1980, passou-se a utilizar a categoria "mulheres", que foi resultado de críticas oriundas do feminismo negro e do terceiro mundo. Por fim, a partir dos anos de 1990, passou-se a utilizar com mais frequência categoria "relações de gênero", influenciada pelo 
pós-estruturalismo. Essa fase tem na obra de Joan Scott e Judith Buther suas principais referências.

A autora salienta que pensar o feminismo a partir de diferentes ondas reforça a ideia de que há um centro irradiador das ideias, que, em suma, são os países desenvolvidos do hemisfério norte e, por outro lado, há o hemisfério sul, que está às margens desse centro. $\mathrm{O}$ que significa que as ondas ou as categorias de "mulher", "mulheres" e "gênero", citadas acima, nasceram em um centro irradiador das ideias e posteriormente, com um atraso considerável, espalharam-se para os países do hemisfério sul.

Segundo a autora, a articulaçao entre "gênero" e "pós-colonialismo" é uma outra perspectiva crítica do feminismo que é recente na historiografia do Cone Sul, cuja proposta é ler o mundo a partir das margens e não a partir do centro: "O pressuposto é de que, a partir das margens, e não a partir do "centro", o mundo se lê melhor e, dessa forma, se poderia ter um projeto crítico e transformador, com uma nova visão de futuro" (PEDRO, 2010:10). Essas críticas são fundamentadas principalmente nas concepções de Spivak, que considera o terceiro mundo como ponto de partida para suas reflexões críticas:

A crítica pós-colonial reconsidera a história a partir dos colonizados, e tenta recuperar as "vozes baixas" da história. Questiona os estatutos assumidos da historiografia ocidental, suas omissões, suas perspectivas (PEDRO, 2010: 10).

Assim, também utilizaremos das concepções de Spivak no que se refere ao problema da mudez enfrentada pela mulher no contexto do colonialismo e do patriarcalismo indiano inerente ao mesmo problema, considerando a realidade cultural indiana, ou seja, um patriarcado distinto do patriarcado europeu. Dessa forma, o artigo Pode o subalterno falar?(2010) nos permitirá refletir sobre as razões que inviabilizam à mulher subalterna tanto o direito de falar quanto, e principalmente, o direito de ser ouvida. Nesse sentido, entende-se que o papel da mulher intelectual oriunda do mundo colonizado pode e deve ser fundamental para promover a discussão que visa descortinar o processo de silenciamento ao qual o sujeito subalterno do gênero feminino foi culturalmente submetida. Spivak se insere nesse contexto como uma intelectual que questiona a si mesma em função do perigo que envolve os intelectuais que defendem os subalternizados, pois tais intelectuais, na ânsia de dar voz ao gênero feminino marginalizado, podem também representá-la equivocadamente, impossibilitando que elas falem por si mesmas. Spivak utiliza, como base de sua análise crítica, o ritual do suttee que era praticado na Índia até que os britânicos o proibiram com o argumento de que tal proibição era para a proteção à vida da mulher, já que não se deveria 
dispor da vida apenas para seguir uma tradição local na qual o gênero feminino era submetido ao sacrifício por um patriarcado não europeu.

Os intelectuais pós-coloniais apesar de se diferenciarem quanto ao objeto de pesquisa individual, há entre eles um consenso em torno da preocupação com a marginalização social, cultural, econômica e de gênero a que as pessoas são submetidas nas colônias. Nesse sentido, a crítica pós-colonial se detém, sobretudo, em questões de classe, gênero e raça, rejeitando os discursos fundamentados em polaridades que explicam a realidade do Outro a partir de categorias binárias, como podemos observar na obra de Edward Said, intitulada Orientalismo: o Oriente como invenção do Ocidente (2003). Essa obra de Said é considerada como o marco institucional dos estudos Pós-Coloniais, cuja proposta é a desconstrução da visão ocidentalista e eurocêntrica sobre o oriente colonizado, caracterizado ao longo da história europeia como sinônimo de barbárie, de não civilização, aquele espaço que estaria à margem do centro irradiador de saber que seria a Europa.

Nessa perspectiva, o escritor palestino é um dos mais importantes críticos literário e cultural, pois mostra como o ocidente construiu uma imagem equivocada e estereotipada do oriente. Segundo o autor, o ocidente se constituiu culturalmente a partir do contato com o nãoeuropeu. Assim, podemos constatar que foi através do contato com hábitos culturais distintos daqueles praticados no ocidente que o europeu julgou-se detentor de uma cultura superior e construiu sua própria identidade.

Nesse diálogo profícuo com Said, incorporamos outro autor que também contribui com esse debate acalorado, que é Tomaz Tadeu da Silva. O autor, em sua obra denominada Identidade e diferença (2000), afirma que a identidade é construída por meio da diferença e pode ser caracterizada por símbolos representativos que fazem parte da cultura de determinado grupo. Sendo assim, a cultura é o elo de atribuição de significados por meio das representações que podem ser simbólicas ou sociais.

Após a publicação inaugural de Said, ocorreram também cooperações reflexivas de indianos como P.Chartterjee, H.Bhabha e R. Guha, a já mencionada Gayatri Spivak; dos latino-americanos Aníbal Quijano e Walter Mignolo. No Caribe, o Pós-Colonialismo foi desenvolvido por Frantz Fanon, Aime Césaire, Edouard Glissant, Fernando Ortiz e Roberto Fernandez Retamar. No Brasil, esses estudos são desenvolvidos por diversas instituições de ensino superior tais como as universidades federais de Minas Gerais, Rio de Janeiro, Santa Catarina, São Paulo, entre outras. 
O principal objeto de investigação dos Estudos Pós-coloniais é a literatura elaborada durante e após a ocupação colonial. Tal literatura preocupa-se em verificar como a sociedade é representada em seus aspectos culturais e políticos. As obras literárias utilizadas pelos Estudos Pós-coloniais foram produzidas por autores que viviam nas regiões que foram colonizadas, como a Índia, Ásia, África, Caribe e América Latina, e suas experiências são valorizadas seja na condição de defensores das metrópoles com suas respectivas representações, seja na condição de críticos à dominação colonial com todas as suas expressões. Analisam os efeitos políticos, sociais e principalmente os efeitos identitários que as regiões colonizadas sofreram durante o processo de colonização e de descolonização. Na literatura se problematiza, ainda que embasada em representações ficcionais, os aspectos culturais e políticos herdados da cultura colonizadora e a partir dessa percepção, as abordagens pós-coloniais vislumbram a construção de novos valores para se pensar a identidade do colonizado, minimizando as influências das nações imperialistas.

As perspectivas pós-coloniais emergem do testemunho colonial do terceiro mundo.Se traduzem em discursos nos quais as minorias que compõem as divisões geopolíticas de Leste e Oeste, Norte e Sul buscam a desconstrução daqueles discursos ideológicos oriundos da modernidade os quais buscam hegemonizar as histórias de diferentes nações, raças, comunidades e povos. Em suma, buscam a desconstrução dos binarismos e a construção de novos valores nos quais as histórias dos povos colonizados possam ser reescritas e também resignificadas continuamente. Dessa forma,

Reconstituir o discurso da diferença cultural exige não apenas uma mudança de conteúdos e símbolos culturais; uma substituição dentro da mesma moldura temporal de representação nunca é adequada. Isto demanda uma revisão radical da temporalidade social na qual histórias emergentes possam ser escritas; demanda também a rearticulação do signo no qual possam inscrever identidades culturais (BHABHA, 1998:240).

Assim, a preocupação de grande parte dos teóricos pós-coloniais, como o próprio Bhabha, é que o objetivo não é substituir um modelo de dominação por outro, mas sim, buscar novas formas de liberdade nas quais as possibilidades de construção de novos valores, a fim de repensar a história dos povos colonizados, estejam presentes. Para tanto, faz-se necessário um diálogo com as raízes identitárias para que esses povos tenham ciência de que eles possuem um passado e que, a partir desse passado, eles possam se abrir na interação com o mundo e construir o presente de forma contínua. 
Nesse sentido, o papel desempenhado pelo intelectual oriundo das sociedades póscoloniais tem sido primordial e ao mesmo tempo arriscado. Na tentativa de fazer com que os povos marginalizados possam repensar sua história ou sua identidade, podem cair na armadilha ideológica imperial que é a de representar, por meio do discurso, os povos subalternos, não oferecendo a estes o poder de fala. Se o oficio do intelectual pós-colonial é árduo, o que dizer sobre a intelectual pós-colonial que está envolvida duplamente com o problema da subalternidade primeiro por uma questão de gênero e depois, pela condição de colonizada?

O artigo intitulado Pode o subalterno falar? propõe a uma reflexão discursiva sobre o papel do intelectual pós-colonial e principalmente da intelectual no sentido de discutir as opressões de gênero presentes nas sociedades pós-coloniais. A autora se preocupou com os perigos de se repetir por meio do discurso intelectual as mesmas formas de opressão que anteriormente o subalterno colonizado foi submetido por não ter o direito de fala, ou melhor, por não ter sua fala ouvida. Spivak faz uma crítica ao próprio grupo subalternity studies do qual faz parte, conclamando os intelectuais, principalmente as intelectuais - já que a autora questiona principalmente o problema da opressão do subalterno feminino - a refletir a questão se realmente o subalterno feminino pode falar, ou se sua fala está sendo mediada por outras pessoas, nesse caso as intelectuais pós-coloniais.

A autora parte de uma crítica aos intelectuais do Primeiro Mundo, em especial a Michel Foucault e Gilles Deleuze, pois, para ela, os intelectuais ocidentais são cúmplices de práticas discursivas nas quais o subalterno é silenciado constantemente. Nessa perspectiva, o subalterno foi construído historicamente pelo ocidente, como afirma Spivak: "A produção intelectual ocidental é de muitas maneiras cúmplice dos interesses econômicos internacionais do ocidente" (SPIVAK, 2010:20).

A cumplicidade da produção intelectual do ocidente é tão evidente que podemos constatar, dialogando com Said (2012), que a produção literária ocidental ou as literaturas de viagens foram elementos primordiais ao descrever o Outro da Europa como aqueles que estavam às margens da sociedade europeia devido à sua inferioridade cultural. De acordo com Said, "O oriente, quando não era apenas um lugar em que se comerciava, estava cultural, intelectual e espiritualmente fora da Europa e da civilização europeia” (SAID, 2012:112). Dessa maneira, a literatura de viagem foi forjada no sentido de mostrar ao europeu uma visão do oriente extremamente tipificada e categorizada, e o não-europeu foi considerado como culturalmente inferior e portando objeto de domínio do europeu. Foi através dessa literatura 
de viagem que foram construídas utopias imaginárias nas quais o oriente é considerado até os dias atuais como um local exótico e perigoso.

Assim, percebemos claramente a conivência do intelectual ocidental na construção do Outro da Europa e Spivak parte dessa critica aos intelectuais ocidentais para chamar a atenção dos intelectuais pós-coloniais para que estes não reproduzam as mesmas estratégias de dominação a que o colonizado foi submetido. Sua crítica parte da premissa de que o intelectual não deve tentar falar pelo subalterno e sim abrir caminhos para que estes tenham voz e sejam ouvidos.

Em o Subalterno pode falar? Spivak está preocupada principalmente com a mudez do sujeito subalterno feminino, em especial com o problema enfrentado pela mulher indiana quando se confrontam as tradições locais com os valores cristãos do ocidente representados pela força colonial britânica. Nessa perspectiva, o subalterno do gênero feminino está entre duas forças superiores: a do patriarcado indiano mantido pela tradição local e a imperial inglesa que recusa essa tradição e promove sua dissolução. A diferença de gênero, mesmo na subalternidade, é perceptível e gritante, pois,

\footnotetext{
No contexto do itinerário obliterado do sujeito subalterno, o caminho da diferença sexual é duplamente obliterado. A questão não é a da participação feminina na insurgência ou das regras básicas da divisão sexual do trabalho, pois em ambos os casos há "evidência". É mais uma questão de que, apesar de ambos serem objetos da historiografia colonialistas e sujeitos da insurgência, a construção ideológica de gênero mantém a dominação masculina. Se no contexto da produção colonial, o sujeito subalterno não tem história e não pode falar, o sujeito subalterno feminino, está ainda mais profundamente na obscuridade (SPIVAK, 2010:66/67).
}

Fica evidenciado, dessa forma, que apesar do sujeito subalterno masculino não ter voz diante do discurso ideológico imperial, ele não permite que o sujeito subalterno feminino tenha voz, ou seja, ele está reproduzindo a ideologia dominante, pois, a tradição local o legitima com a finalidade de manter a mulher silenciada e submissa ao patriarcado local. Assim, o sujeito subalterno feminino, além de ser silenciado pelo imperialismo europeu, não lhe é dado o direito de voz nem quando este é confrontado com suas tradições. Nessa perspectiva considera-se que a mulher subalterna é duplamente colonizada.

Portanto, diante dessa constatação, podemos proceder argumentando, em diálogo com Spivak, que o fato de ser do gênero feminino, pobre e negra faz com que a mulher esteja envolvida subalternamente de três formas: primeiro pelo fato de ser mulher, depois o fator 
social e por último a questão de ser negra, que é um das características que mais influenciam na marginalização do indivíduo.

Ao falar sobre o papel do intelectual pós-colonial e também sobre o papel da intelectual, Spivak está buscando principalmente abordar o problema da mudez do subalterno do gênero feminino mulher e nesse sentido a intelectual pós-colonial tem função primordial, ainda que se diferencie das demais subalternas. É nessa diferença em relação às outras subalternas do gênero feminino que Spivak se encaixa, pois apesar de ser oriunda de uma sociedade colonial, seu grau de consciência é outro e o seu local de fala também. Nesse sentido, ela poderia estar justamente tentando falar pela mulher subalterna indiana ou representando-a, ou mesmo em busca de memórias perdidas. A autora reconhece esse perigo e argumenta que escolheu um exemplo indiano, o ritual do suttee que é o sacrifício das viúvas, pelo fato de conhecer bem e poder falar sobre essa realidade que a autora considera específica da Índia. Assim fala Spivak:

Nasci na Índia e lá recebi minha educação, desde o Ensino Fundamental até o Ensino Superior, incluindo dois anos de pós-graduação. Assim, o exemplo indiano que utilizo pode ser visto como uma nostálgica investigação das raízes perdidas de minha própria identidade. Embora eu saiba que não se pode entrar livremente nos meandros das "motivações", afirmo que meu projeto principal é destacar a variedade positivista-idealista de tal nostalgia. Volto-me ao material indiano porque, na ausência de um treinamento disciplinar avançado, esse acidente de nascimento e de educação me proveu de um sentido de um cenário histórico (...). No entanto, o caso especifico indiano não pode ser tomado como representativo de todos os países, nações e culturas que podem ser invocados como o Outro da Europa, como um Eu (SPIVAK, 2010:49).

Nesse sentido, a autora reconhece o próprio lugar incômodo de fala, mas tenta e conclama a todos os intelectuais pós-coloniais a se autoquestionarem continuamente sobre a pergunta que não pode calar: O subalterno pode realmente falar? Diante dessa pergunta, a autora questiona o próprio lugar de onde teoriza. Com isso, mostra-se consciente da própria cumplicidade com relação à representação do subalterno:

Pode-se afirmar que não há nenhum sujeito subalterno irrepresentável que não possa saber e falar por si mesmo. A solução do intelectual não é se abster da representação. O problema é que o itinerário do sujeito não foi traçado de maneira ao oferecer um objeto de sedução ao intelectual representante (...) A questão que se apresenta é: como podemos tocar a consciência do povo, mesmo quando investigamos sua política? Com que voz-consciência o subalterno pode falar? (SPIVAK, 2010: 61).

\section{Fististorírias}


Assim, a proposta da autora é a busca por estratégias com as quais o subalterno possa falar e que sua voz seja realmente ouvida. Como foi dito acima, o sujeito subalterno feminino está envolvido duplamente, pois é silenciado pela tradição local e também pela ideologia imperial europeia. Nessa perspectiva, Spivak analisa o ritual do suttee que é legitimado pela tradição indiana, porém é proibido pela lei britânica. Nesse sentido, o gênero feminino é considerado um objeto que está entre essas duas forças opostas. A autora apresenta o ritual do suttee e o problematiza, mostrando a fragilidade dessas duas forças antagônicas.

Segundo a tradição indiana:

A viúva hindu sobe a pira funerária do marido morto e imola-se sobre ela. Esse é o sacrifício da viúva-a transcrição convencional da palavra sânscrita para a viúva seria sati. Os primeiros colonos britânicos a transcreveram como suttee. O ritual não era praticado universalmente e não era relegado a uma casta ou classe (SPIVAK, 2010:94).

Segundo Spivak, esse ritual foi abolido pelos britânicos e é compreendido como uma sentença em que homens brancos estão salvando mulheres de pele escura de homens de pele escura. Por outro lado, há outra sentença produzida pela tradição nativa que argumenta: “As mulheres realmente queriam morrer" (SPIVAK, 2010:94). Para Spivak, ambas as sentenças não procuraram ouvir a voz da consciência da subalterna do gênero feminino, pois a mulher realmente poderia, por amor ao seu marido, sacrificar-se; mas há também o fato de a mulher decidir-se por não se sacrificar e isto, na sociedade indiana, seria passivo de punição.

Mesmo supondo que o ato de abolição do suttee pelos britânicos tenha sido um ato admirável, Spivak desconfia das verdadeiras intenções dos britânicos, ou seja, será que realmente eles estavam interessados em proteger a mulher colonizada, ou mais uma vez impor seus costumes aos nativos, já que a tradição cristã proíbe a prática do suicídio? A autora deixa claro que não está defendendo o ritual do Sutte e sim mostrando as fragilidades das duas posições. Assim como o ritual do suttee se mascara por trás de uma ideologia de recompensa divina, o erro imperial inglês é o de se legitimar com o argumento de uma missão social.

A autora dialoga como o autor britânico de concepção marxista Edward Thompson para mostrar a contradição do argumento imperial, pois, ao mesmo tempo em que os britânicos condenam o suttee como uma prática selvagem e cruel contra a mulher, por outro lado, as perseguições religiosas na Europa levaram muitas mulheres a serem mortas, consideradas bruxas. Thompson argumenta: 
(...) praticamente um século antes do costume do suttee começar a chocar a consciência inglesa, das orgias de queima as bruxas e perseguições religiosas tenham se sentido daquela forma com relação ao suttee. Mas as diferenças lhes pareciam ser que as vitimas de suas crueldades eram torturadas por uma lei que as considerava criminosas, enquanto que as vitimas do suttee eram punidas não por uma ofensa, mas sim pela fraqueza física que as punha a mercê do homem. O ritual parecia provar uma tamanha depravação e arrogância como nenhuma outra ofensa humana havia revelado (THOMPSON, In. SPIVAK, 2010:104/105).

Para Spivak, essa explicação de Thompson é imprecisa no sentido de mostrar que a ideologia imperial está realmente preocupada com a morte da mulher pelo simples fato destas serem mais frágeis em relação ao homem. Ou seja, Thompson justifica por um lado a morte de inúmeras mulheres pelo fato destas terem sido julgadas e condenadas e por outro lado legitima o caráter de "missão social" o fato dos britânicos abolirem o sacrifício das viúvas.

Quanto ao fato da tradição indiana de defender o ritual do suttee, Spivak mostra ainda outra fragilidade. Na Índia, a viúva não poderia ser herdeira dos bens do marido, mas em certas regiões, como Bengala, a viúva poderia herdar. Dessa forma, para além de uma questão de tradição, está o significante material do fato da viúva ser herdeira do marido.

Nesse sentido, da mesma forma que a tradição imperial parece dissimular sua defesa em relação à mulher frágil e subalterna, a tradição indiana também se utiliza da dissimulação ao convencer a viúva de que por devoção e amor ao marido esta deve se oferecer ao sacrifício. $\mathrm{Na}$ verdade o elemento impulsionador seriam os bens materiais do marido falecido.

Por outro lado, retomando a sentença "as mulheres realmente queriam morrer", podemos construir outro argumento. Nas regiões da Índia onde a mulher não poderia herdar propriedades, a morte se justificaria pelo fato de que caso se recusasse a morrer, seria severamente punida e marginalizada socialmente, o que representa uma modalidade de morte em vida. O que uma mulher em uma sociedade com valores patriarcais tão arraigados faria sem nenhum recurso financeiro, sem nenhuma proteção? Podemos constatar que o aspecto econômico poderia, ainda que de forma velada, influenciar na morte das viúvas, tanto pela impossibilidade desta ser herdeira do marido quanto pela ausência deste, pois neste momento a mulher não teria subsídios para continuar a viver, uma vez que já estaria morta/marginalizada socialmente.

Spivak oferece a resposta à pergunta que intitula o artigo, Pode o subalterno falar? ao analisar a prática do suttee a partir de duas representações distintas, que são: a ideologia imperial europeia proibindo que o ritual seja praticado e, por outro lado, o patriarcalismo indiano defendendo o ritual inerente às suas tradições. A autora conclui que o subalterno, e 
mais especificamente o subalterno feminino, realmente não pode falar. Isso se traduz não no sentido literal da expressão e sim na perspectiva de que o subalterno feminino não tem sua voz ouvida, uma vez que assim como o homem colonizado tem sua personalidade construída pelo colonizador, a mulher tem a sua personalidade usurpada duplamente: pelo colonizador imperialista e pelo patriarcado local, ambos homens. Sendo assim, não tem o direito de se autoconstruir. Sua voz é silenciada pelo fato de não ser considerada como um sujeito autônomo. Quando ocorre a possibilidade de autonomia, esta é consolidada de forma trágica.

Spivak argumenta sobre essa possível autonomia do subalterno feminino através do exemplo de uma jovem indiana que fazia parte de grupo que lutava pela independência da Índia. Segundo Spivak, quando esta foi incumbida de assassinar um inimigo político, acreditando que não seria capaz de tal ato que lhe foi imposto e ao mesmo tempo tendo consciência de que não poderia simplesmente desobedecer a ordem, esta jovem comete o radical ato de autonomia, ou seja, o suicídio. Deve-se ressaltar que quem a incumbiu do assassinato eram líderes políticos e homens, portanto, a jovem estava subordinada a líderes masculinos que lutavam por uma causa comum, qual seja, a independência da Índia. Porém, ainda que em luta pelo mesmo propósito, é perceptível a dominação de gênero, pois se a jovem não cumprisse a ordem de levar a cabo o assassinato, seria punida por tais líderes masculinos.

Nas palavras da autora:

Uma jovem de 16 ou 17 anos, Bhuvasneswari Bhaduri, enforcou-se no modesto apartamento de seu pai, no norte de Calcutá, em 1926. O suicídio se tornou um enigma, já que como Bhuvasneswari estava menstruada na época, claramente não se tratava de um caso de gravidez ilícita (SPIVAK, 2010:123).

O fato de a jovem ter cometido suicídio constitui-se um paradoxo. Isso porque uma vez que a jovem escolheu não matar, ainda que perdendo sua própria vida e nesse sentido, em uma sociedade colonial e patriarcal castradora, este foi o momento em que a vontade da mulher prevaleceu. Ela se autodeterminou. E ainda nessa perspectiva, o fato de a jovem ter esperado menstruar mostra que houve uma intervenção na tradição indiana do sutte, na qual Spivak acredita que ela conseguiu reescrever o ritual o subvertendo, uma vez que no ritual do sutte era proibido que a mulher se autoimolasse enquanto estivesse menstruada. Paradoxalmente, mostra também que ao aguardar a menstruação, a jovem ainda estava presa 
às tradições, pelo fato de não permitir que a sociedade ao buscar as causas para sua morte, pudesse justificá-la como uma gravidez ilícita.

Com esse exemplo, Spivak reconhece, de forma enfática, a contribuição da mulher intelectual na visibilidade e consequente questionamento e resignificação da marginalização da mulher colonizada:

Tenho conhecimento da vida de Bhuvasneswari por meio de relatos de conexões com sua família, Antes de investigá-las mais minuciosamente, indaguei a uma mulher, bengali, uma fisólofa e estudiosa do sânscrito, cuja produção intelectual inicial é quase idêntica à minha, para iniciar o processo. Obtive duas respostas: a) Por que, quando suas duas irmãs, Saileswari e Raseswari, levaram vidas tão plenas e maravilhosas, você está interessada na infeliz Bhuvasneswari? b) Perguntei a suas sobrinhas, parece que foi o caso de um amor ilícito (SPIVAK, 2010:124).

Isso deixa clara a cumplicidade de algumas mulheres intelectuais com o fato da mulher subalterna não ter direito à fala. Percebam que o fato de a intelectual questionada por Spivak acreditar que falar ou escrever sobre a vida de duas mulheres que haviam certamente seguido as tradições, casado-se e que por isso viviam "plenamente felizes" era mais viável do que falar de uma mulher que transgrediu essa tradição com uma atitude altamente consciente em relação à sua personalidade e ao seu corpo colocando fim à própria existência.

Dessa forma, no mundo colonial no qual o colonizado não possui o direito de fala, a personalidade da subalternidade do gênero feminino historicamente foi impossibilitada, pois foi duplamente usurpada. Nesse sentido, torna-se urgente a empreitada por parte dos intelectuais e, mais especificamente das intelectuais pós-coloniais, para se permitir um espaço de liberdade em que a mulher colonizada possa se autoconstruir, autogerir, autorrepresentar, enfim, falar e ser, realmente, ouvida.

\section{Referências Bibliográficas}

BHABHA, Homí.K. O local da cultura. Trad: Myriam Ávila, Eliana Lourenço de Lima Reis, Gláucia Renate Gonçalves. Belo Horizonte: Editora UFMG, 1998.

BONNICI, Thomas. O Pós-Colonialismo e a Literatura. Maringá: Editora da Universidade Estadual de Maringá, 2000.

BONNICI, Thomas.Conceitos-chaves da teoria pós-colonial. Maringá: Editora da Universidade Estadual de Maringá, 2005.

BUTLER, Judith. Él género en disputa: El feminismo y la subversión de la identidad, 2007. Traducción de Maria Antônia Muñoz. Ediciones Paidós Ibérica, SA.

SPIVAK, Gayatrí Ghakravort. Pode o subalterno falar? Trad:Sandra Regina Goulart

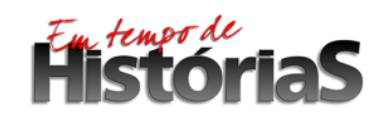

(PPGHIS/UnB) No. 25, Brasília, Ago- Dez 2015 ISSN 2316-1191 
de Almeida, Marcos Pereira Feitosa e André Pereira Feitosa, Belo Horizonte: Editora: UFMG, 2010.

SAID, Edward W. Orientalismo: o Oriente como invenção do Ocidente. Trad: Tomás Rosa Bueno. São Paulo: Companhia das Letras, 2012.

SILVA Tomaz Tadeu da. Identidade e Diferença: A perspectiva dos estudos culturais/ Tomaz Tadeu da Silva (org). Stuart Hall, Kathryn Woodward. Petrópolis, Rj: Vozes, 2000.

SCOTT, Joan. Gênero: uma categoria útil para análise histórica, 1995. Tradução de Christine Rufino Dabat \&Maria Betânia Ávila.

PEDRO, Joana Maria. Relações de gênero como categoria transversal na historiografia contemporânea, 2010. Texto é resultado de dados coletados para a pesquisa "Do feminismo ao gênero - circulação de teorias e apropriações no Cone Sul (1960-2008)", iniciada em março de 2010, com financiamento do CNPq. 